\title{
Symposium Article
}

\section{Extreme Risks in Financial Markets and Monetary Policies of the Euro-Candidates}

\author{
HUBERT GABRISCH ${ }^{1}$ \& LUCJAN T ORLOWSKI ${ }^{1,2}$ \\ ${ }^{1}$ Halle Institute for Economic Research, Kleine Märkerstrasse 8, 06108 Halle (Saale), \\ Germany. E-mail: Hubert.Gabrisch@iwh-halle.de \\ 2J.F. Welch College of Business, Sacred Heart University, 5151 Park Avenue, Fairfield, \\ CT 06825, USA. E-mail: OrlowskiL@sacredheart.edu
}

\begin{abstract}
This study investigates extreme tail risks in financial markets of the euro-candidate countries and their implications for monetary policies. Our empirical tests show the prevalence of extreme risks in the conditional volatility series of selected financial variables, that is, interbank rates, equity market indexes and exchange rates. We argue that excessive instability of key target and instrument variables should be mitigated by monetary policies. Central banks in these countries will be well-advised to use both standard and unorthodox (discretionary) tools of monetary policy while steering their economies out of the financial crisis and through the euro-convergence process.

Comparative Economic Studies (2011) 53, 511-534. doi:10.1057/ces.2011.9;

published online 1 September 2011
\end{abstract}

Keywords: monetary policy rules, tail risks, euro-convergence, global financial crisis, market risk

JEL Classifications: E44, F31, G15, P34

\section{INTRODUCTION}

Volatility shocks associated with the global financial crisis of the period 2007-2009 have magnified extreme risks in both mature and emerging financial markets (Orlowski, 2010b). This study investigates the proliferation and scale of these risks as well as their repercussions for the conduct of monetary policies in the euro-candidate countries.

Extreme tail risks result from the leptokurtic distribution of financial market variables. This phenomenon is well known in practice and widely 
512

researched in the literature. In essence, a leptokurtic distribution means that observations are more dispersed around the mean value and assume more extreme values (ie have fatter tails) than they do in a normal distribution. Thus financial variables that are close to the mean value in normal market periods may be widely dispersed at turbulent times, which results in their 'fat tails'. Interest rates and other financial variables that serve as instruments or policy monitoring parameters for central banks are characterized by such distribution. These variables are vulnerable to sudden volatility outbursts, and thus may become very unstable (Orlowski, 2010b). Extreme tail risks of these financial variables impair implementation of monetary policy when the policy is based on parsimonious rules that commonly assume normal distribution of key variables, thus ignoring their leptokurtic time-pattern. In essence, extreme volatility shocks inhibit monetary policy transmission mechanisms and reduce the efficiency of standard interest-rate policies (Curdia and Woodford, 2010; Svensson, 2010).

We argue that outbreaks of extreme tail risks in the euro-candidates during financial crises call for extraordinary monetary policy responses that cannot be based on standard Taylor rules. To mitigate tail risks, monetary policies ought to be comprehensive and supplemented with appropriate macro- and micro-prudential regulatory policies. These policy requirements, coupled with international coordination, are precepts of our proposed new financial stability framework for economies converging to the euro.

Our empirical investigation is focused on detecting extreme tail risks (or fat tails) in the distribution of selected financial market variables, namely, equity market indexes, interbank rates and exchange rates, all of which are relevant for the conduct of monetary policies in converging economies. We analyze volatility patterns of these variables in the euro-candidate countries that are pursuing relatively independent monetary policies with flexible exchange rates, including the Czech Republic, Poland, Hungary and Romania. For comparative purposes Slovakia is also included. Although it has already adopted the euro as of January 2009, it embraced a flexible exchange rate regime during the euro-convergence period. The selected countries have been pursuing inflation targeting without a formal disclosure of a specific instrument rule (Orlowski, 2005, 2008a). However, a recent examination of their monetary policies' possible adherence to open-economy instrument rules (Orlowski, 2010a) suggests that, in the case of the Czech Republic and Poland, the inflation gap is still a predominant driver of central bank reference rates. In contrast, adjustments of the Hungarian reference rate are associated mainly with changes in the exchange rate gap. There is no evidence that the central bank reference rates in these countries respond to the desire to lower the output gap. In light of these findings, we support the argument of 
Svensson (2003) that a targeting rule is less rigid than an instrument rule. However, we intend to examine whether the flexible inflation targeting pursued by our selected countries has played any role in lowering extreme tail risks associated with the recent financial crisis.

Our analysis is focused on three types of market risks that directly affect monetary policy decisions: equity market risk, interest rate risk and exchange rate risk. We employ GARCH volatility tests augmented with the in-mean GARCH variance as a proxy of a risk premium or discount. For the purpose of evaluating the degree of leptokurtosis, that is, the prevalence of fat tails in the conditional volatility patterns, we apply the generalized error distribution (GED) parameterization. Our working assumption is that the estimated GED parameters of the examined financial market variables are considerably lower than 2 , indicating the existence of fat tails.

The next section reviews the literature on the sources of extreme risks and their severity during the financial crisis of the period 2007-2009. The setup of the analytical models is explained in the subsequent section. The empirical results based on the GARCH-M-GED testing are presented and discussed in the section after that. The penultimate section suggests monetary policy responses to extreme risks embedded in the examined financial market variables within our proposed new financial stability framework for the eurocandidates. The final section provides a summary.

\section{MONETARY POLICY RULES: ACCOUNTING FOR TAIL RISKS}

A key question in our analysis is whether monetary policy can be effective in containing extreme risks, such as those precipitated by the global financial crisis of the period 2007-2009. There is no common answer to this question in the literature. A standard prescription based on the actual policies following the Great Depression of the 1930s is that monetary policy cannot effectively contain the crisis because it is unable to lower the cost of credit in the presence of severe shocks to credit markets. The ability of the central banks to stabilize the financial system is also constrained as large budget deficits are often financed by money creation, which leads to high inflation and currency depreciation. ${ }^{1}$ Notwithstanding these hindrances, we find plausible the arguments by Mishkin (2009) and Jobst (2009) that there is a

\footnotetext{
${ }^{1}$ This holds true particularly for emerging market economies, as fiscal stimulus applied in response to financial crisis results in higher public debt and higher debt servicing cost thus increasing the risk of sovereign default. See the examination of the limited capacity of emerging market countries to engage in fiscal stimulus by Reinhart and Rogoff (2009: chapter 12).
} 
leading role for monetary policy in overcoming the crisis and ensuring financial system stability in the future. The question remains whether emerging market economies, including the euro-candidates, are equipped with sufficient monetary policy tools to respond effectively to financial crises.

With respect to the 2007-2009 crisis, there is a general consensus that the substantial monetary policy easing aimed at alleviating its damaging real economy effects was indispensable (Curdia and Woodford, 2010). Without these liquidity injections the cost of credit would be much higher, significantly increasing credit spreads and possibly precipitating systemic risk. These expansionary monetary policies reduced interest rates on risk-free securities and narrowed credit spreads. Consequently, by the end of 2009, credit spreads decreased to the levels preceding the outbreak of the financial crisis in August 2007. In essence, central banks in advanced economies have become 'lenders of first (rather than last) resort'. They have engaged extensively in providing liquidity to banks that had lost trust in each other, and suspended interbank lending, particularly in the aftermath of the global credit freeze that followed the collapse of Lehman Brothers Inc. in early October 2008. In retrospect, the vast and unprecedented liquidity injections by the Federal Reserve and other central banks helped alleviate a severe economic recession. There is no consensus, however, whether, in the aftermath of the crisis, monetary policy should depart from discretionary easing and return to 'the set of principles for setting interest rates that worked well during the Great Moderation', as suggested by Ahrend (2008) and Taylor (2009).

The answer to this question lies in the distribution of key monetary policy and other relevant financial variables and in the underlying behavior of agents in a monetary economy. In fact, the leptokurtic distribution of these variables is ubiquitous (Mishkin, 2009; Orlowski, 2010b). Under such a distribution, the volatility of these variables is well contained during normal market periods, but it tends to increase significantly at turbulent times, resulting in extreme tail risks. Therefore, approximations of variable fluctuations based on the assumption of a normal or Gaussian distribution tend to severely underestimate the de facto risks during turbulent or financial crisis periods.

The roots of extreme tail risks are quite complex. Among their main causes are unanticipated corrections of asset prices and, as in the recent crisis, a bank credit freeze stemming from an increasing liquidity risk due to the rapidly depreciating value of assets that cannot be easily liquidated. It has been pointed out in the literature that money supply is strongly and positively related to asset prices (Minsky, 1982a, b; Borio and Drehmann, 2009a, b). Rising profit expectations increase asset prices, making speculation on assets more profitable. As the balance sheet of financial institutions expands, 
their willingness to lend, resulting in an endogenous expansion of the money supply. An imminent asset price bubble might induce higher market interest rates due to the rising demand for funds to invest in assets. If asset-price inflation passes through to income inflation, the central bank's loss function would signal higher losses, and the bank would increase its policy rate. A minor 'not-unusual' surprise (Minsky, 1982a) or an exogenous shock-like contagion eventually punctures the asset price bubble, reversing the endogenous expansion of the money stock. As credit markets freeze, debt depreciation, deflation and output decline follow. This is the point when a tranquil period turns into a turbulent one, reflected in elevated volatility and higher risk of monetary and financial variables. Hence, the underlying leptokurtic distribution of key monetary and financial variables seems to be in line with Minsky's financial fragility hypothesis (Minsky, 1982a, b), and Kindleberger's $(1988,2005)$ history of 'manias and crashes', and it is consistent with the origin and the course of the United States housing market implosion that initiated the 2007-2009 global financial crisis (Orlowski, 2008b).

The leptokurtosis or extreme tail risks in a market economy pose challenges for central banks as they obscure the loss and the reaction functions. ${ }^{2}$ The first challenge is that both functions are based on judgments about the development of flow aggregates, such as commodity prices, output and interest rates, assuming that deviations from target or equilibrium are caused either by the business cycle or by stochastic shocks. However, leptokurtosis results mainly from asset price movements, caused by unstable judgments of agents about the long-term development of prices of financial or real assets. Indeed, there is evidence that central bank policies become ineffective during the periods of monetary tightening aimed at abating asset price inflation. Minsky observed this problem in the United States during the credit crunch of 1966, the liquidity squeeze of the period 1969-1970 and the recession of the period 1974-1975. Each time, the financial industry evaded monetary tightening by devising financial innovations and extending credit. Hence, Minsky concluded that 'monetary constraint in a situation in which ongoing investment activity leads to a rising demand for finance is effective only as it forces a sharp break in asset values' (Minsky, 1982a, p. 77). The most recent example of the Minsky phenomenon is the Federal Reserve's attempt to reduce inflationary pressures by increasing the federal funds rate in the period 2004-2006. Financial innovations devised to circumvent these restrictions contributed to the asset price bubble, and subsequently became toxic (Orlowski, 2008b).

\footnotetext{
${ }^{2}$ We omit discussion of other important assumptions such as the central bank's knowledge of a welfare function or a clear articulation of optimal policy rules (see Polito and Wickens, 2008).
} 
516

The second problem lies with the central bank's reaction function. During the tranquil period preceding the global financial crisis of the period 2007-2009, monetary authorities adopted non-discretionary, instrument-rulebased policies with adjustments of the short-term interest rate as the predominant policy tool (Taylor, 1993). An inflation target, supplemented with output gap and/or exchange rate stability, served as a key policy goal. The underlying assumption for these Taylor-rule-based policies was a normal distribution of policy variables over time. Svensson (2003) questioned the effectiveness of rigid Taylor rules under asymmetric distribution of the variables and instead proposed target rules with more discretion. The recent financial crisis has underscored the importance of active responses to extreme tail risks that are associated with a leptokurtic distribution of key monetary variables and stem from their volatility outbursts (Orlowski, 2010b). For this reason, non-discretionary policies based unconditionally on Taylor rules are likely to be inadequate for containing extreme tail risks. In essence, the underlying risks associated with episodes of elevated volatility of the policy variables can be managed more effectively with discretionary policies.

Adjustments of short-term interest rates constituted a predominant monetary policy instrument during the 'Great Moderation' period. Such a parsimonious approach seems no longer relevant in light of the recent crisis, which has precipitated the need for massive liquidity injections to financial institutions through central banks' purchases of risky assets. As a result, monetary policies of both highly developed and emerging market economies can no longer simply focus on a single policy target. The policy formulas have become more complex, incorporating as a target not only price stability, but also economic growth, exchange rate stability and, perhaps most importantly, containment of a systemic risk. This may require monitoring of individual categories of risk such as the market, liquidity, credit, default, exchange rate, counter-party and other risks faced by the financial sector and the real economy as increases in these risks may translate into higher systemic risk.

The third challenge for central banks is rooted in the erosion of their independence. This does not mean a loss of independence stemming from government interference, but rather a loss of power due to liberalization and deregulation of financial markets. With such constraints on their power, central banks have limited ability to counteract financial crises, particularly in emerging market economies whose currencies are not used as international reserves. A theoretical explanation of this phenomenon can be found in Wolfson (2002), who states that the debt-deflation character of a crisis turns into a debt-devaluation interaction through which the volatility of key monetary and financial variables becomes strongly affected by international 
events. In the tranquil period, free capital flows and deregulated markets induce local agents to take loans denominated in the reserve currency instead of in the local currency as long as interest rates on the reserve currency credit are lower than on the local currency credit. As a result, the local central bank de facto and gradually loses economic independence, because the increasing inflows of foreign capital are difficult to sterilize. Higher domestic policy rates attract more foreign currency-denominated borrowing and induce domestic currency appreciation. However, in the case of financial crisis accompanied by local currency depreciation, holders of debt denominated in foreign currency may face a greater default risk. Then, the ability of the central bank to act as a lender of last or 'first' resort is limited and depends on its access to reserve currency.

An erosion of central bank independence has affected the euro-candidate countries, all with non-reserve currencies, particularly in the aftermath of a far-reaching liberalization of capital flows and financial sector deregulation as necessitated by their active preparations to satisfy the Maastricht convergence criteria (Gabrisch, 2009). Moreover, high interest rate differentials between their domestic and foreign currency-denominated credits have strengthened incentives for local agents to take debt in foreign currency, although this effect has not been uniform among the examined countries (Hanousek et al., 2009). A rising demand for foreign credit has bolstered capital inflows. In addition, widening interest rate spreads have contributed to the appreciation of local currencies, the steady course of which has diminished the exchange rate risk.

We now proceed to evaluation of the magnitude and precipitation of extreme tail risks of monetary variables in the euro-candidate countries in order to suggest an appropriate course of monetary policies during preparations for the euro adoption. A strong evidence of extreme tail risks in these countries would call for a more discretionary approach to monetary policy, disconnected from the steady course implied by a Taylor rule.

\section{MODEL SETUP AND DATA}

Monitoring equity market risk is an important task for monetary authorities, particularly at times of financial distress. Although the volatility of equity market risk does not customarily enter into the central bank's loss function or instrument rules, it has far-reaching reverberations for the credit markets, capital flows, financial and tangible investments, and exchange rate movements, all of which affect the conduct and direction of monetary policy. In fact, it has been documented in the literature that precipitation of equity 
market risk, proxied by increases in the VIX volatility index in the United States, had strong spillover effects on credit and liquidity risks during the course of the recent financial crisis (Mizen, 2008; Orlowski, 2008b). In essence, the volatility dynamics of equity markets are a good indication of investors' confidence in the country's financial stability and resiliency against external financial contagion. For this reason, equity market risk dynamics could serve as an important monitoring device for monetary policy makers.

Monitoring interest rate risk is equally crucial for monetary policy decision making, because its proliferation reduces the effectiveness of monetary policy instrumentalization. Central banks of the euro-candidates ought to consider a relative interest rate risk that can be captured by the volatility dynamics of short-term interest rates in their respective countries vis-à-vis the volatility of the corresponding interest rates in the eurozone. Such an approach lets them set a time path for the interest rate risk premium vis-à-vis the eurozone, which is important for the successful implementation of monetary policy during the course of convergence to the euro.

Exchange rate risk is the third market risk category. This risk is tied to the instability of a possible exchange rate target and to the unreliability of the exchange rate channel of monetary policy transmission. Needless to say, this channel serves as a focus of monetary policy implementation in the economies converging to a common currency. Elevated exchange rate risk at stressful market periods confuses asset valuation and credit pricing in the banking sector. It subsequently necessitates higher interest rates and tighter credit. Monetary authorities must react to jumps in exchange rate volatility as they distort the functioning of the exchange rate channel of policy transmission, which has been proven to be unstable in the euro-candidate countries (Golinelli and Rovelli, 2005; Orlowski, 2005, 2008a; Kočenda and Valachy, 2006; Kočenda et al., 2006). We therefore estimate conditional volatility of exchange rate changes in response to key determinants of exchange rates, that is, the uncovered interest parity and the purchasing power parity, in our selected countries.

We also investigate the evolution of risks in the selected euro-candidate countries during the past decade, with special attention to the propagating of the 2007-2009 global financial crisis. In order to capture risk dynamics, we examine changes in the conditional volatility of major equity market indexes, relative short-term interest rates and daily changes in the euro value of local currencies. Our sample period starts January 3, 2000 and ends August 7,2009, with some adjustments for different inception dates for the secondary market trading of long-term government bonds in individual countries. In order to investigate the conditional volatility dynamics we employ GARCH(p,q)-M-GED, the generalized autoregressive conditional heteroscedasticity with the in-mean 
variance and generalized error distribution, testing. In particular, we focus on the overall risk premium or discount, reflected by the positive or negative value of the in-mean GARCH variance coefficient, the M-component. We further examine the degree of leptokurtosis, which is measured by the extent to which the GED parameter is less than 2, and the relative proportion of shocks or 'news' to volatility reflected by the ARCH(p) coefficients to the persistency in volatility implied by the GARCH(1) coefficient. The time distribution of conditional standard deviations from the GARCH series allows us to examine the subperiods of risk contraction and proliferation.

\section{Equity market risk}

In our conditional mean equation for the return process $r_{t}$, changes in the log of local equity market indexes $E_{t \mid r t}$ serve as a dependent variable. Changes in the log of the German DAX40 index $E_{t}^{D A X 40}$, and the log of the GARCH variance $\sigma_{t-1}^{2}$ serve as regressors:

$$
\Delta \log \left(E_{t \mid r t}\right)=\beta_{0}+\beta_{1} \Delta \log \left(E_{t}^{D A X 40}\right)+\beta_{2} \log \sigma_{t-1}^{2}+\varepsilon_{t}
$$

The corresponding $\operatorname{GARCH}(1,1)$ conditional variance specification is

$$
\sigma_{t}^{2}=h_{0}+h_{1} \varepsilon_{t-1}^{2}+\gamma_{1} \sigma_{t-1}^{2}
$$

with the ARCH(1) component denoted by $\varepsilon_{t-1}^{2}$ and the GARCH(1) denoted by $\sigma_{t-1}^{2}$.

\section{Interest rate risk}

Changes in the domestic short-term interest rate, the 3-month interbank lending rate, $i_{t}^{3 M}$, are modeled in relation to changes in the 3-month Euribor $i_{t}^{3 M}$ and in the log exchange rate $s_{t}$. The inclusion of both independent variables allows for testing their possible impact on the key monetary policy instrument variable and explains the degree of monetary policy autonomy. The conditional mean specification with the in-mean log GARCH variance is

$$
\Delta i_{t \mid r t}^{3 M}=\beta_{0}+\beta_{1} \Delta i_{t}^{3 M}+\beta_{2} \Delta \log \left(s_{t}\right)+\beta_{3} \log \left(\sigma_{t-1}^{2}\right)+\varepsilon_{t}
$$

The corresponding GARCH(p, 1) conditional variance specification is

$$
\sigma_{t}^{2}=h_{0}+h_{1} \varepsilon_{t-1}^{2}+h_{2} \varepsilon_{t-2}^{2}+\cdots+h_{p} \varepsilon_{t-p}^{2}+\gamma_{1} \sigma_{t-1}^{2}
$$

High-order ARCH terms are applied in this case as they proved to be significant in preliminary testing. 


\section{Exchange rate risk}

In this model, we employ the GARCH-M-GED process ascertaining daily changes in the local currency value of the euro $s_{t}$ as a function of changes in the differential between the 3-month interbank offer rates of the eurocandidate country $i_{t}^{3 M}$ and the eurozone (Euribor) $i_{t}^{3 M E}$, and changes in the term spread on 10-year less 3 -month sovereign bond yields $i_{t}^{10 Y}-i_{t}^{3 M}$ as a proxy of inflation expectations. The model also includes changes in the local equity market index $E_{t}$ as a regressor in the conditional mean equation in order to reflect the impact of equity capital flows on exchange rates. The conditional mean equation is represented by

$$
\begin{aligned}
\Delta \log (s)_{t \mid r t}= & \beta_{0}+\beta_{1} \Delta\left(i_{t}^{10 Y}-i_{t}^{3 M}\right)+\beta_{2} \Delta\left(i_{t}^{3 M}-i_{t}^{3 M E}\right) \\
& +\beta_{3} \Delta E_{t}+\beta_{4} \log \left(\sigma_{t-1}^{2}\right)+\varepsilon_{t}
\end{aligned}
$$

The corresponding GARCH(p, q) conditional variance equation is

$$
\begin{aligned}
\sigma_{t}^{2}= & h_{0}+h_{1} \varepsilon_{t-1}^{2}+h_{2} \varepsilon_{t-2}^{2}+\cdots+h_{p} \varepsilon_{t-p}^{2} \\
& +\gamma_{1} \sigma_{t-1}^{2}+\gamma_{2} \sigma_{t-2}^{2}+\cdots+\gamma_{q} \sigma_{t-q}^{2}
\end{aligned}
$$

As in the previous cases, the ARCH(p) terms $h_{p} \varepsilon_{t-p}^{2}$ represent the impact of 'news' or shocks to volatility, and the GARCH(q) terms $\gamma_{q} \sigma_{t-q}^{2}$ reflect the role of persistency in volatility. ${ }^{3}$ In all cases, the selection of $\mathrm{p}$ and q orders is obtained by minimizing the Akaike and the Schwartz information criteria.

\section{ESTIMATION RESULTS}

\section{Equity market risk developments}

The results of the GARCH-M-GED estimation, equations 1 and 2, of changes in local equity market indexes relative to changes in the German DAX40 are shown in Table 1. Changes in the German stock market index drive the euro-candidates indexes in the same direction, but at a varied degree of significance. The most significant relationship is detected for Hungarian and Slovak markets; the Polish and Czech markets show a less significant

${ }^{3}$ In the preliminary testing, we augmented the conditional volatility series (equations 2, 4 and 6) with an EU accession dummy variable assuming the value of one for the period following the accession and zero for the preceding period, in order to ascertain the impact of the EU membership on risk developments in the investigated series. This variable has proven to be insignificant in all examined cases, suggesting that the EU accession has not decisively contributed to the financial stability of the euro-candidates. 
Table 1: Changes in (the log of) equity market indexes vis-à-vis the changes in (the log of) the German DAX40 index. GARCH-M-GED estimation - equations 1 and 2. Daily series; sample period January 3, 2000 - August 7, 2009

\begin{tabular}{|c|c|c|c|c|c|}
\hline Variables $\Downarrow$ & Czech Republic & Poland & Hungary & Romania & Slovakia \\
\hline \multicolumn{6}{|c|}{ Conditional mean equation (coefficient $\times 100$ ) } \\
\hline Constant term & $-6.633^{*}$ & $-1.092^{* *}$ & 1.972 & $6.263 * *$ & $0.052 * * *$ \\
\hline German DAX40 index & $9.306^{*}$ & $1.493^{*}$ & $17.998^{* * *}$ & 8.407 & $3.541 * * *$ \\
\hline $\log (\mathrm{GARCH})$ & $-0.084^{* *}$ & $-1.304^{* * *}$ & 0.018 & $0.065^{* *}$ & 0.005 \\
\hline \multicolumn{6}{|c|}{ Conditional variance equation } \\
\hline Constant & $0.001^{* * *}$ & $0.001 * *$ & $0.001 * * *$ & $0.001 * * *$ & $0.001 * * *$ \\
\hline $\mathrm{ARCH}(1)$ & $0.118^{* * *}$ & $0.052^{* * *}$ & $0.089 * * *$ & $0.334^{* * *}$ & $0.094 * * *$ \\
\hline $\mathrm{GARCH}(1)$ & $0.868 * * *$ & $0.942 * * *$ & $0.887^{* * *}$ & $0.655^{* * *}$ & $0.654 * * *$ \\
\hline GED parameter & $1.387^{* * *}$ & $1.356^{* * *}$ & $1.418^{* * *}$ & $1.045^{\star * *}$ & $0.568 * * *$ \\
\hline \multicolumn{6}{|l|}{ Diagnostic statistics } \\
\hline Log likelihood & 7,432.9 & $6,905.5$ & $7,114.0$ & $7,094.3$ & $8,595.1$ \\
\hline AIC & -5.936 & -5.514 & -5.681 & -5.665 & -6.859 \\
\hline SIC & -5.919 & -5.498 & -5.665 & -5.650 & -6.843 \\
\hline Durbin-Watson stat. & 1.86 & 1.93 & 1.89 & 1.70 & 1.99 \\
\hline
\end{tabular}

$* * *$ denotes significance at $1 \%,{ }^{* *}$ at $5 \%$ and $*$ at $10 \%$.

Notes: All variables are in first differences; $t$-statistics are in parentheses; $A I C=$ Akaike information criterion, SIC = Schwartz information criterion; stock market indexes are Prague PX50, Warsaw WIG20, Budapest BUX, Bucharest BET(L), Bratislava SXSAX16.

Source: Authors' own estimation based on Datastream data

dependence on German market movements, and the reaction of the Romanian market is insignificant. There is a negative risk premium on the Czech and Polish equity markets, as implied by the negative sign of $\log (\mathrm{GARCH})$ terms in the conditional mean equation. In contrast, the risk premium on the Romanian market is significantly positive. The risk premia results for Hungary and Slovakia are inconclusive.

Consistent with the behavior of global equity markets, volatility of the Czech, Polish and Hungarian markets is highly persistent, as implied by GARCH coefficients in the conditional variance equations being close to unity. The ARCH-type shocks to volatility in these three markets play a relatively minor role. The Romanian market conditional volatility series displays very different characteristics with a stronger role for ARCH terms and a lower degree of GARCH persistency. Arguably, the Romanian market is the most susceptible to unexpected shocks to volatility among the analyzed group of equity markets. More importantly from the standpoint of our analytical objectives, the estimated GED parameters in all five equity markets are significantly lower than 2, indicating considerable leptokurtosis, that is, pronounced extreme tail risks. Evidently, volatility in these markets tends to escalate considerably during turbulent market periods, while it remains subdued at 
tranquil times. Another focal point of our analysis is the sum of ARCH and GARCH coefficients. It is very close to unity in the cases of the Czech, Polish, Hungarian and Romanian markets, which suggests no visible gains in volatility convergence. The sum is significantly below one only for the Slovak market, implying an overall reduction in volatility, and thus a significant decline in market risk in this new member of the eurozone.

The time-path of conditional volatilities for the Czech, Polish, Hungarian, Slovak and Romanian stock market indexes is shown in Figures 1(a)-(e). In all five cases, market risk surged during the peak of the recent global financial crisis. The largest volatility upswings in the GARCH series took place during the peak of the crisis in the October 10 - November 15, 2008 period. All five stock markets took an unprecedented hit on October 10, in the aftermath of the Lehman Brothers collapse that triggered the subsequent global credit market freeze, coupled with international investors' withdrawal of capital from emerging markets. The October 10 market plunge was followed by series of up-and-down swings of the euro-candidates' equity markets, with the elevated volatility not receding to its pre-crisis pattern until July-August of 2009. The analysis of volatility dynamics with respect to the pre- and the postEU accession periods is also revealing. The GARCH residuals seem to recede gradually during the pre-accession periods in all five markets, but there is no discernible containment of volatility since the respective EU accessions. It can be therefore argued that EU membership has not engendered stability in equity markets of the euro-candidates. Moreover, euro adoption did not contain stock market volatility in Slovakia. This seems to suggest that entering the common currency system does not insulate a local stock market from large external shocks. The volatility patterns in Slovakia should be of concern for monetary authorities in the euro-candidates because euro adoption does not automatically bring about gains in financial stability.

Thus, equity markets in the euro-candidates remain highly vulnerable to exogenous shocks, as proven by the significant leptokurtosis in their volatility dynamics series. ${ }^{4}$ The likelihood of disruptive spillover effects of elevated equity market risk into domestic credit, investment and economic growth at times of financial distress remains very high.

\section{Interest rate risk}

The empirical results for equations 3 and 4 are shown in Table 2. From the perspective of our study's objectives, the most striking outcome is the extreme

${ }^{4}$ Similar conclusions can be found in Hanousek et al. (2009) and Hanousek and Kočenda (2011), who examine the impact of macroeconomic announcements and external market news on volatility of Central European equity markets. 
H Gabrisch \& LT Orlowski
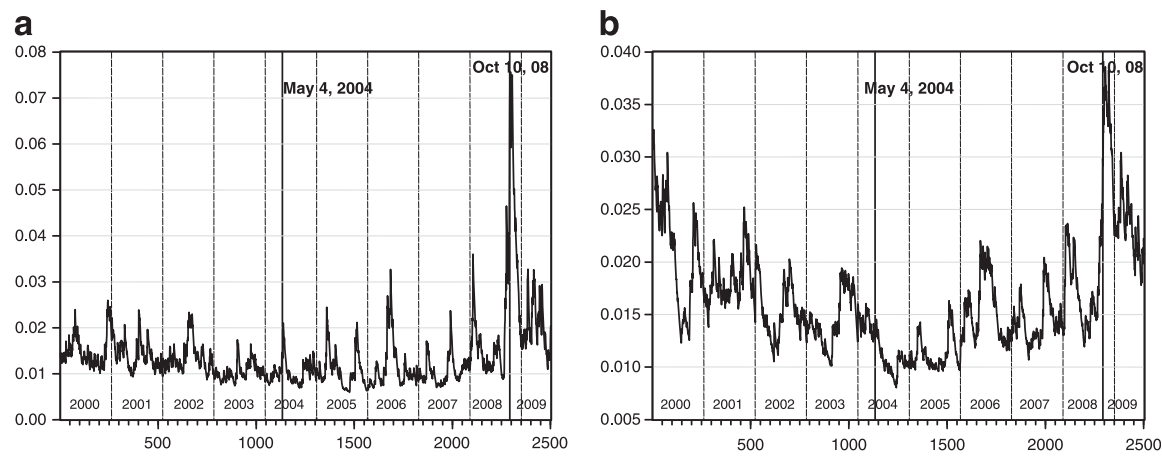

C

\section{d}
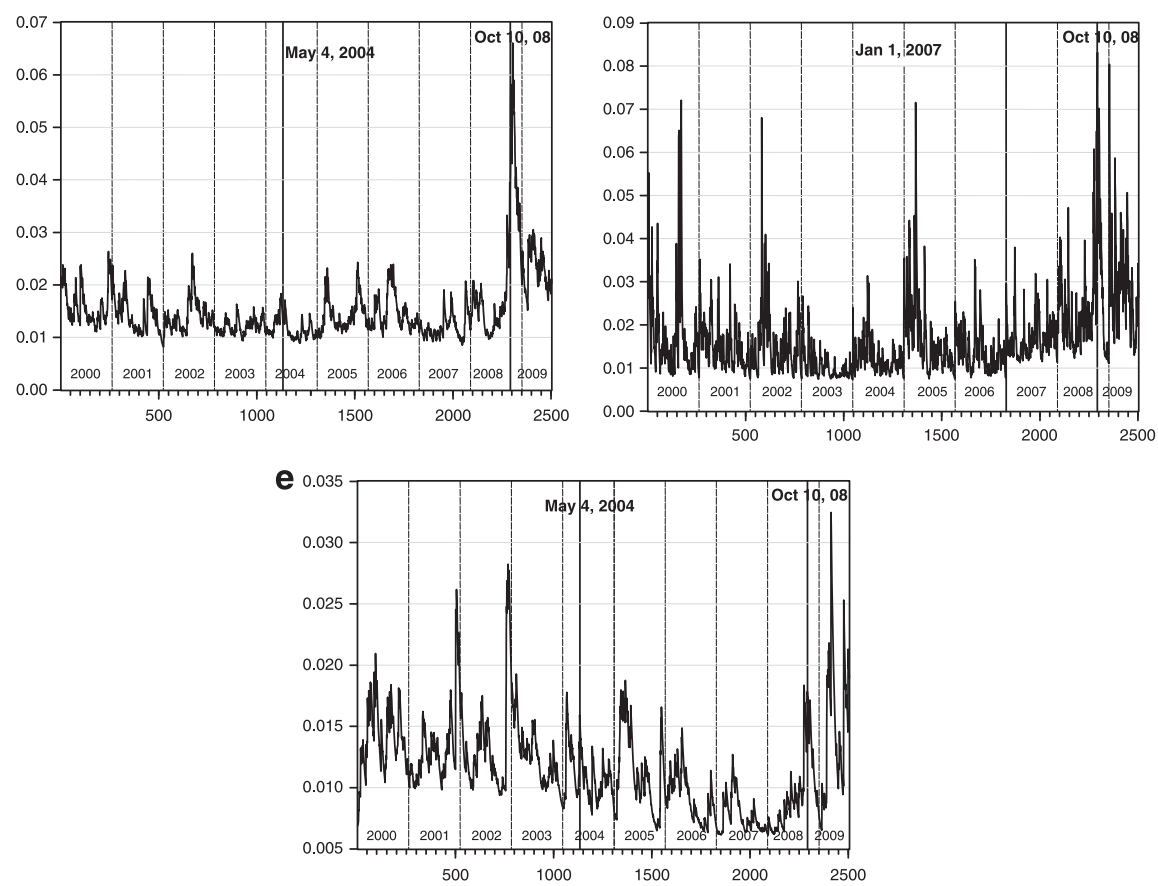

Figure 1: GARCH conditional standard deviation for equity market index series vis-à-vis German DAX40 (a) The Czech Republic: Prague SE PX Index; (b) Poland: Warsaw WIG20 Index; (c) Hungary: Budapest BUX Index; (d) Romania: Bucharest BET(L) Index; (e) Slovakia: Bratislava SXSAX16 Index Source: Own estimations based on Datastream data

leptokurtosis of the interbank rates volatility series in all five cases, which is more pronounced than is the leptokurtosis of the equity market series. The estimated GED parameters for the interbank markets of the euro-candidates are all very low, indicating the prevalence of extreme tail risks. This finding 
Table 2: Changes in 3-month market interest rates vis-à-vis the changes in Euribor 3-month rates and the log of the exchange rate against the euro. GARCH-M-GED estimation - equations 3 and 4. Daily series; sample period January 3, 2000 - August 7, 2009

\begin{tabular}{|c|c|c|c|c|c|}
\hline Variables $\Downarrow$ & Czech Republic & Poland & Hungary & Romania & Slovakia \\
\hline \multicolumn{6}{|c|}{ Conditional mean equation (coefficient $\times 100$ ) } \\
\hline Constant term & $-0.124^{* * *}$ & $-0.000 * * *$ & $0.000 * * *$ & $-38.801 * * *$ & $-28.041 * * *$ \\
\hline EURIBOR3M & 0.000 & 0.000 & $0.000 * * *$ & $0.000 * * *$ & -0.000 \\
\hline Log(Exchange rate) & 0.000 & 0.000 & -0.000 & $0.017 * * *$ & 0.000 \\
\hline $\log (\mathrm{GARCH})$ & $-0.000^{* * *}$ & $-0.000 * * *$ & $-0.000 * * *$ & $-11.468^{* * *}$ & $-3.972 * * *$ \\
\hline \multicolumn{6}{|c|}{ Conditional variance equation } \\
\hline Constant & $0.000 * * *$ & $0.006 * * *$ & $0.000 * * *$ & $0.002^{* * *}$ & $0.000 * * *$ \\
\hline $\mathrm{ARCH}(1)$ & $0.537 * * *$ & $2.314^{* * *}$ & $0.780 * * *$ & $0.006^{* * *}$ & $0.012^{* * *}$ \\
\hline $\mathrm{ARCH}(2)$ & $-0.280^{* * *}$ & $-1.309 * *$ & $-0.480 * * *$ & $-0.002^{* * *}$ & $-0.008^{* * *}$ \\
\hline $\mathrm{ARCH}(3)$ & - & - & $-0.179^{* * *}$ & - & $0.000^{* * *}$ \\
\hline $\mathrm{GARCH}(1)$ & 0.520 & $0.789 * * *$ & $0.876^{* * *}$ & $0.412^{* * *}$ & $0.652 * * *$ \\
\hline GED parameter & $0.266^{* * *}$ & $0.234^{* * *}$ & $0.155^{* * *}$ & $0.174 * * *$ & $0.380 * * *$ \\
\hline \multicolumn{6}{|l|}{ Diagnostic statistics } \\
\hline Log likelihood & $10,634.12$ & $4,301.81$ & $7,779.824$ & $5,502.916$ & $5,832.546$ \\
\hline AIC & -8.490 & -3.430 & -6.208 & -4.390 & -4.962 \\
\hline SIC & -8.469 & -3.409 & -6.185 & -4.369 & -4.937 \\
\hline Durbin-Watson stat. & 2.020 & 2.314 & 1.852 & 1.107 & 1.670 \\
\hline
\end{tabular}

$* * *$ denotes significance at $1 \%,{ }^{* *}$ at $5 \%$ and * at $10 \%$.

Notes: All variables are in first differences; $t$-statistics are in parentheses; $A I C=$ Akaike information criterion, SIC = Schwartz information criterion.

Source: Authors' own estimation based on Datastream data

supports the claim that short-term interest rates of the euro-candidates are likely to jump significantly in times of financial distress, underscoring exceptional vulnerability of their banking sectors to external shocks. In addition, there is a significant risk discount in the cases of the Romanian and Slovak rates as implied by the negative $\log (\mathrm{GARCH})$ coefficients in the conditional mean equations. These reactions are likely related to the very high initial interest rate risk premia in these two countries as well as to changes in interbank borrowing from local rather than eurozone banks. At the same time, there is a very small interest rate risk discount detected for the Czech, Polish and Hungarian interbank rate series. The conditional volatility series of interbank rates is highly persistent for Polish and Hungarian interbank markets, as signified by high values of GARCH coefficients. Interbank rates remain vulnerable to ARCH-type shocks with non-uniform diffusion in the cases of the Czech, Polish and Hungarian rates.

The graphical displays (Figures 2(a)-(e)) of the GARCH conditional standard deviation series show large jumps in interest rate volatility for the Czech Republic, Hungary and Romania coinciding with the October 10, 2008 turbulence in global financial markets. Poland is a notable exception. 
H Gabrisch \& LT Orlowski
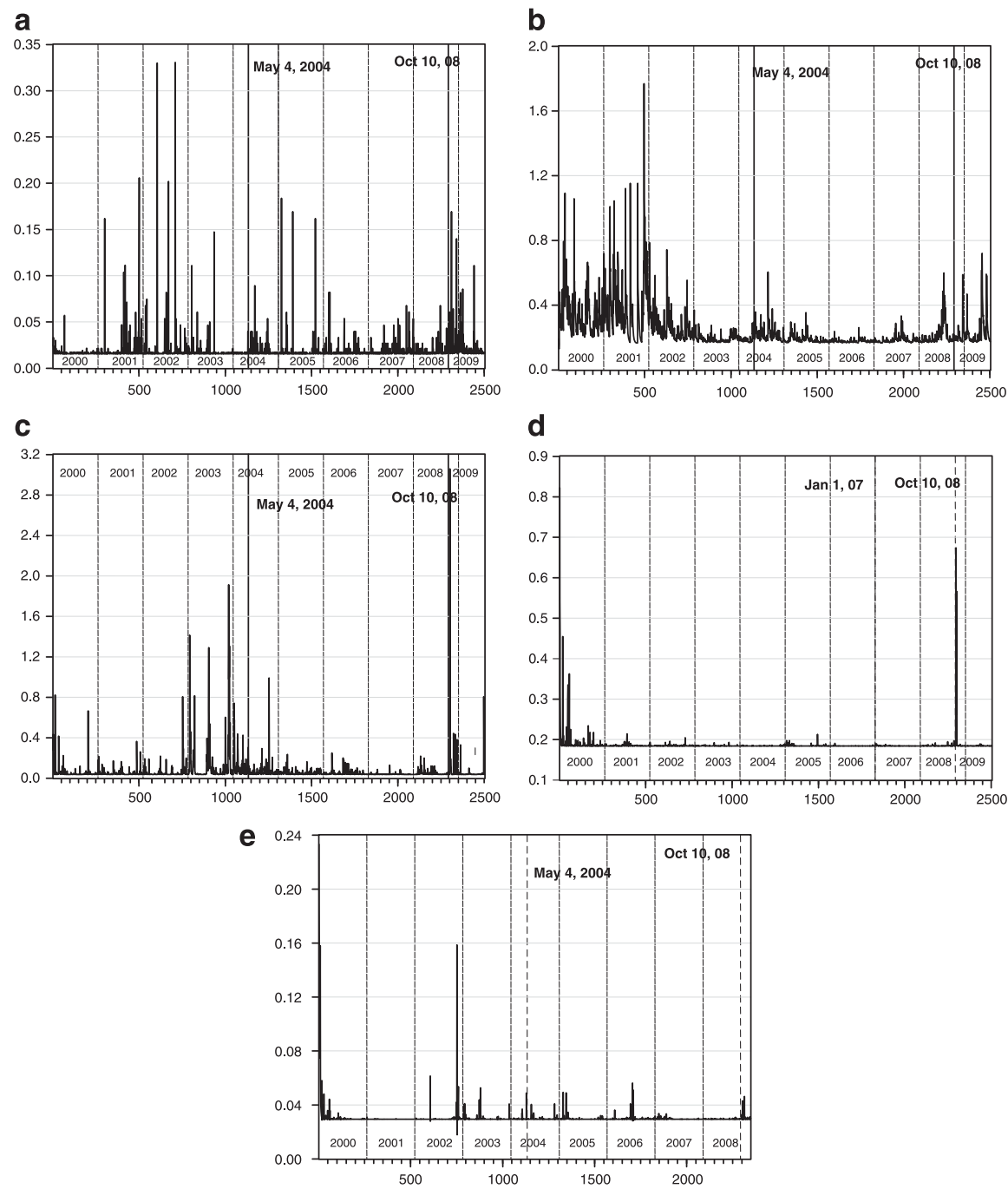

Figure 2: $\operatorname{GARCH}(\mathrm{p}, \mathrm{q})-\mathrm{M}-\mathrm{GED}$ conditional standard deviations of daily changes in local $3 \mathrm{M}$ interbank rates in relation to changes in 3M Euribor and the exchange rate, equations 3 and 4. January 3, $2000-$ August 7, 2009 daily series. (a) Czech interbank rates, $\operatorname{GARCH}(2,1)-\mathrm{M}-\mathrm{GED}$; (b) Poland's interbank rates $\operatorname{GARCH}(2,1)-M-G E D ;(c)$ Hungary's interbank rates $\operatorname{GARCH}(3,1)-M-G E D$; (d) Romania's interbank rates $\operatorname{GARCH}(2,1)-M-G E D$; (e) Slovakia's interbank rates $\operatorname{GARCH}(3,1)-\mathrm{M}-\mathrm{GED}$

Source: Authors' own estimation based on Datastream data

In all, relative interest rate volatility in the euro-candidate countries remains very high. It also remains elevated in Slovakia, in spite of its being a member of the eurozone. These high interest rate risk premia make the financial systems 
of the euro-candidates susceptible to large interest rate shocks and contagion effects from global crises. Under such circumstances, a strict adherence of monetary policy to interest rate rules seems both implausible and counterproductive for creating the foundations of financial stability.

\section{Exchange rate risks}

The exchange rate volatility model is multivariate and thus more elaborate than the equity market and the interbank rate models, due to the overall statistical significance of the regressors included in the conditional mean equation. The estimation results of the exchange rate volatility series specified by equations 5 and 6 are shown in Table 3 .

The results reveal that changes in euro values expressed in local currencies are highly sensitive to changes in local stock market indexes for all examined countries, with the notable exception of Slovakia, as implied by the negative

Table 3: Changes in (the $\log$ ) exchange rates vis-à-vis the euro as a function of changes in: the term spread on sovereign bond yields, the $3 \mathrm{M}$ interest rate differential and the stock market index. GARCH-M-GED estimation - equations 5 and 6. Daily series; sample period January 3, 2000 - August 7, 2009 (April 1, 2005 - August 7, 2009 for Romania; January 3, 2003 - December 31, 2008 for Slovakia)

\begin{tabular}{|c|c|c|c|c|c|}
\hline Variables $\Downarrow$ & Czech Republic & Poland & Hungary & Romania & Slovakia \\
\hline \multicolumn{6}{|c|}{ Conditional mean equation (coefficient $\times 100$ ) } \\
\hline Constant term & -0.002 & $0.346^{*}$ & $-0.164^{*}$ & $0.191^{*}$ & -0.000 \\
\hline Term spread & $0.317 * *$ & $1.232 * * *$ & $1.990 * * *$ & $-0.056^{* *}$ & 0.044 \\
\hline Interest rate differential & 0.293 & $1.218^{* * *}$ & $2.124^{* * *}$ & $-0.290 * * *$ & 0.037 \\
\hline Stock market index & $-1.483^{* * *}$ & $-5.277^{* * *}$ & $-2.592^{* * *}$ & $-4.055^{* * *}$ & 0.031 \\
\hline $\log (\mathrm{GARCH})$ & -0.002 & $0.034^{*}$ & $0.014^{*}$ & $0.018^{*}$ & -0.000 \\
\hline \multicolumn{6}{|l|}{ Conditional variance equation } \\
\hline Constant & $0.000 * *$ & $0.000 * *$ & $0.000 * * *$ & $0.000 * *$ & $0.000 * *$ \\
\hline $\mathrm{ARCH}(1)$ & $0.204^{* * *}$ & $0.154^{* * *}$ & $0.286^{* * *}$ & $0.339 * * *$ & $0.167 * * *$ \\
\hline $\mathrm{ARCH}(2)$ & $-0.177^{* * *}$ & $-0.102 * * *$ & -0.078 & $-0.263^{* * *}$ & - \\
\hline $\mathrm{ARCH}(3)$ & - & - & $-0.097^{* *}$ & - & - \\
\hline GARCH(1) & $0.969 * * *$ & $0.941^{* * *}$ & $0.891^{* * *}$ & $0.924^{* * *}$ & $0.861 * * *$ \\
\hline GED parameter & $1.050^{* * *}$ & $1.280^{* * *}$ & $0.995^{* * *}$ & $0.939 * * *$ & $0.842^{* * *}$ \\
\hline \multicolumn{6}{|l|}{ Diagnostic statistics } \\
\hline Log likelihood & $9,442.985$ & $8,381.908$ & $9,106.733$ & $4,590.746$ & $9,574.790$ \\
\hline AIC & -8.487 & -7.539 & -8.191 & -8.261 & -9.189 \\
\hline SIC & -8.461 & -7.513 & -8.162 & -8.216 & -9.165 \\
\hline Durbin-Watson stat. & 2.125 & 2.256 & 2.232 & 1.913 & 1.990 \\
\hline
\end{tabular}

$* * *$ denotes significance at $1 \%, * *$ at $5 \%$ and * at $10 \%$.

Notes: All variables are in first differences; $\mathrm{AIC}=$ Akaike information criterion, SIC $=$ Schwartz information criterion; a minus 1-day lag is applied to the Czech 3M Pribor vis-à-vis 3M Euribor; term spread reflects $10 \mathrm{Y}$ less $3 \mathrm{M}$ sovereign bond yields; short-term interest rates are: $3 \mathrm{M}$ Pribor, $3 \mathrm{M}$ Wibor, 3M Bubor, RMIBK3M, 3M Skibor, 3M Euribor; stock market indexes are Prague PX50, Warsaw WIG20, Budapest BUX, Bucharest BET(L), Bratislava SXSAX16.

Source: Authors' own estimation based on Datastream and Eurostat data 
signs of the equity market index coefficients. This suggests that capital inflows to domestic equity markets correspond to the local currency appreciation (euro depreciation), which underpins a strong role of foreign capital inflows in local market movements. A wider term spread on sovereign bond yields (corresponds) to the depreciation of the Polish Zloty (PLN), the Czech Koruna (CZK), the Hungarian Forint (HUF), the Slovak Koruna (SKK), but not the Romanian Leu (RON). In the first four cases, the wider term spread translates into currency depreciation, thus satisfying the purchasing power parity conditions, as it likely reflects rising long-term inflation expectations. The interest rate differential captured by the widening spread between local interbank offer rates and the Euribor rate is associated with the depreciation of CZK, PLN and HUF, contrary to the uncovered interest parity assumptions because local banks are likely to increase borrowings in the local currency when it is expected to depreciate. Romania is again a notable exception. We could not detect a risk premium or discount on local currencies in any of the examined cases, as the $\log (\mathrm{GARCH})$ coefficients in the mean equations are all insignificant. ${ }^{5}$

The conditional volatility of the analyzed series is highly persistent in all five euro-candidates, as implied by GARCH(1) coefficients all being close to unity. The most significant ARCH shocks to volatility are detected for RON, followed by the HUF, CZK and PLN series. Certainly, the most crucial finding of the tests is the very high degree of leptokurtosis in the exchange rate series in all five cases, as implied by the estimated GED parameters significantly lower than 2. Nonetheless, the extreme risk in the case of the exchange rate volatility series is considerably less pronounced than the one detected for the interbank rates series.

Further insights in the time-varying path of exchange rate volatility are provided by GARCH standard deviations shown in Figures 3(a)-(e). During the post-EU accession periods, the conditional exchange rate volatility has remained subdued for CZK, PLN and HUF, but clearly not for RON. It is worth noting that there have been several pronounced volatility jumps in SKK series during this period. However, Slovakia's becoming a member of the eurozone in January 2009 had evidently helped mitigate exchange rate risk in the preceding turbulent months while at the same time exchange rate risk was elevated in the euro-candidate countries, where it has remained elevated in the aftermath of the October 10, 2008 peak of the global financial crisis, with signs of returning to pre-crisis volatility levels only in mid-2009.

\footnotetext{
${ }^{5}$ See Kočenda and Poghosyan (2009) for a more detailed examination of the macroeconomic determinants of the exchange rate risk in the new EU Member States. Using the stochastic discount factor and GARCH-M testing, they provide evidence that both nominal and real economic variables play important role in the determination of exchange rate risk in these countries.
} 
a

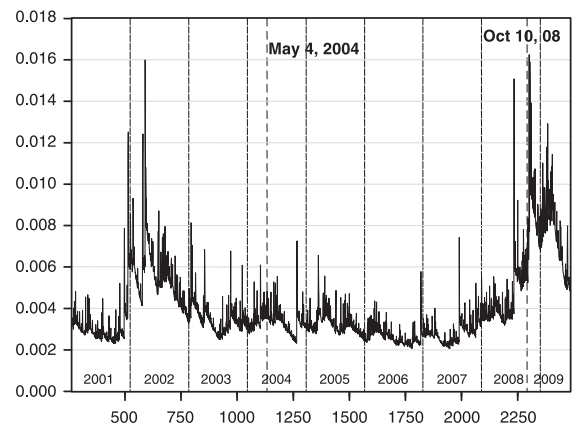

C

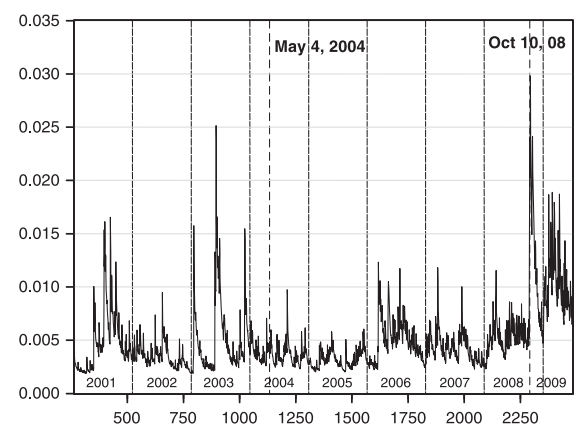

b

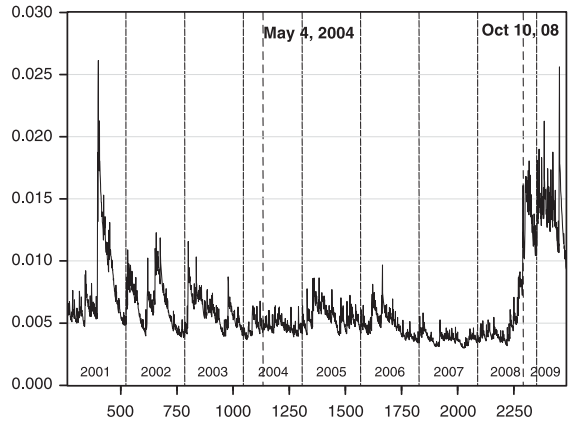

d

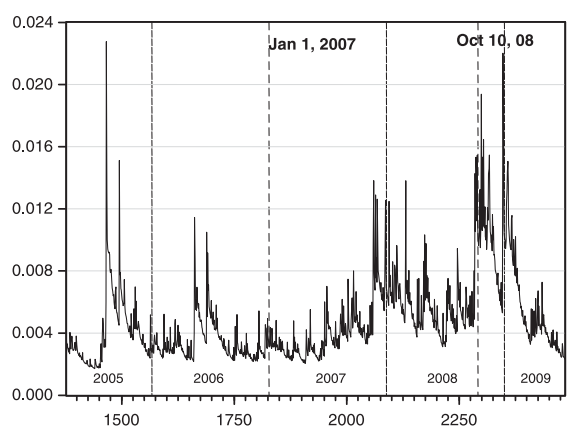

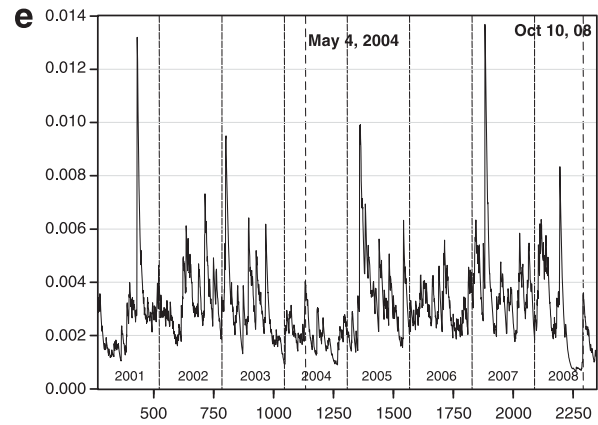

Figure 3: GARCH conditional standard deviations generated from estimations of equations 5 and 6 reported in Table 3. January 3, 2000 - August 7, 2009 daily series. (a) The Czech Republic: GARCH $(2,1)-M-G E D$; (b) Poland: GARCH $(2,1)-M-G E D$; (c) Hungary: $\operatorname{GARCH}(3,1)-M-G E D$; (d) Romania (April 1, 2005 - August 7, 2009 daily series): GARCH(2,1)-M-GED; (e) Slovakia (January 3, 2003 - December 31, 2008 series): GARCH(1,1)-M-GED

Source: Authors' own estimation based on Datastream and Eurostat data

In essence, the 2007-2009 global financial crisis has hampered the process of gaining exchange rate stability in the analyzed countries, with the notable exception of Slovakia, whose euro adoption cushioned the 
transmission of global financial shocks. One may thus argue that the prospects of adopting the euro, including the formal entry to the ERM2, may reduce exchange rate risk in these countries and also lead to a more effective absorption of external shocks.

\section{MONETARY POLICY IMPLICATIONS FOR THE EURO-CANDIDATE COUNTRIES}

Our empirical findings shed new light on the recent monetary policy debate, which White (2009) summarizes as the 'lean versus clean' policy dilemma. The traditional approach assumed that financial crisis episodes are unpredictable, and thus monetary policy should follow a pre-determined rule at all times, and 'clean up' after a crisis. This approach was well suited for the 'happy' period of the Great Moderation epitomized by small business cycle fluctuations and low financial risks. The recent financial crisis engendered more significant fluctuations, provoking the question whether monetary policies can 'lean against the wind' (White, 2009), by being oriented toward containing excessive credit expansion and pre-emptive countering of asset-price bubbles already in the pre-crisis period. Among others, Borio and White (2003) and Svensson (2010) differentiate between the tasks of monetary policy and the tasks of financial stability policy all within a new framework of macro-financial stability. We are led to believe that synchronized monetary and regulatory policies should counteract the shocks that are permanent, that is, those that can permanently imperil financial stability and aggravate systemic risk, rather than those that are transitory.

With respect to the euro-candidate countries, our empirical analysis implies that outbreaks of financial crisis episodes can be signaled, even in seemingly tranquil times, based on the monitoring of tail risks embedded in the behavior of key monetary policy target and instrument variables. Hence, we argue that monetary policies need to take into consideration the task of mitigating these risks. In order to fulfill this task, monetary policies ought to become more unorthodox and seemingly more complex than those based on simple Taylor rules. Such policies should be counter-cyclical, and they should be reasonably restrictive and aimed at preventing an excessive buildup of debt in the economy during the normal market periods. They should become decisively expansionary at times of financial distress in order to increase the supply of loanable funds and sustain bank lending.

We further note that standard forecasting models, based on the key monetary and financial variables such as inflation, interest rates or the output gap, are not very useful for detecting extreme financial market risks 
because they assume mean reversion over a long period. In fact, recent monetary policies of the central banks following such models have turned out to be pro-cyclical and seemingly ineffective for abating asset-price bubbles (Hellwig, 2008; Jobst, 2009). Prior to the recent crisis, reference interest rates that were implied by parsimonious rules à la Taylor were declining in spite of the accelerating credit boom. Thus, they contributed to increasing private debt and rising asset prices. Central banks in the eurocandidate countries followed the same pro-cyclical policy of lowering interest rates as inflation and long-term interest rates declined after EU accession (Orlowski, 2010a).

On the basis of the above arguments, we advocate a new financial stability framework for the euro-candidate countries that includes three basic synchronized components: monetary policy, (macro- and micro-) prudential stability policy and international collaboration.

Monetary policy is a prime component within the suggested framework. In order to respond effectively to possible outbreaks of extreme risks, monetary policy ought to be counter-cyclical and also relatively flexible. Extreme risks can be at least partially mitigated by forward-looking policies based on smoothed forecasts. As suggested by the empirical findings, the episodes of extreme risks, particularly those prevalent in the interbank credit markets, have seriously distorted forecasts of key monetary policy variables. The recent financial crisis has made these forecasts increasingly unreliable and inaccurate. Our study underscores the need to detect leptokurtosis in the forecasting models. This can be done for instance by augmenting GARCH volatility tests with GED parameterization. If the estimated GED parameter is less than 2, leptokurtic distribution is detected. Disturbances of this nature are likely to take place in the future if the monetary authorities of the eurocandidates do not adequately address tail risks through a broad range of emergency measures, such as sterilized interventions, large liquidity injections, currency swap lines, special lending facilities for banks, etc. In essence, effective risk-mitigating policies cannot be based only on interest rate adjustments.

Prudential regulatory policies comprise the second component of the proposed framework. Not only monetary policies, but also prudential regulatory policies should be counter-cyclical and lean against the bubbles whose potential implosion could impair financial system stability, as implied by the 'Geneva Report' (Brunnermeier et al., 2009). In the case of euro-candidate countries, such policies should include regulation aimed at controlling excessive leverage of banks, particularly foreign banks, that engenders pro-cyclical effects. A problem remains that monetary policies customarily assume that commodity and labor markets have sticky prices, while asset 
prices are not sticky, experiencing at times abrupt changes consistent with the prevalence of fat tails. We argue that high leptokurtosis, that is, extreme tail risks associated with abrupt price adjustments stem from asset-price volatility. Asset prices in euro-candidate countries are highly correlated with bank lending, which is strongly influenced by high foreign bank participation in domestic credit markets (Gabrisch, 2010). Substantial credit booms spurred by foreign banks in these countries can threaten the macroeconomic and financial stability of the region. It seems, therefore, necessary to enact regulations to control the excessive leverage of banks, particularly foreigncontrolled ones, that has engendered pro-cyclical effects.

The third component is international collaboration. In hindsight, the extreme risks of financial variables arise from asset-price bubbles generated not only by domestic factors, but also transmitted through external spillovers. Owing to the international transmission of shocks, international coordination of these policies is crucial, particularly for the euro-candidate countries as a group pursuing the joint task of adopting the euro. This is a special requirement for euro-candidates because the engagement of international banks is relatively high in terms of equity and participation in domestic lending. International collaboration should not be limited to emergency situations only, such as the efforts of the Vienna Initiative launched in January 2009 in response to the recent crisis. It should start in seemingly tranquil times simultaneously in host and home countries of international banks. Macro- and micro-prudential regulation and agreements should be mutually coordinated in order to avert possible loopholes and asymmetric effects.

We further advocate that central banks in the euro-candidate countries should take over more responsibility for both monetary and regulatory policies in the future. This is due to pro-cyclical effects of simultaneous actions of banks, households, private companies and the government in both crisis and pre-crisis periods. Private sector expectations in anticipation of the euro adoption are likely to boost both private and public spending, and ultimately improve profitability of financial institutions. Central banks in these countries, as independent institutions, are certainly qualified to steer the smooth euro-convergence process effectively, but they need to account for possible outbreaks of extreme risks in financial markets.

\section{A SUMMARY}

Our study investigates extreme tail risks embedded in the behavior of key monetary and financial variables in four euro-candidate countries: the 
Czech Republic, Hungary, Poland and Romania. We also include Slovakia, already a euro-member, for comparative purposes. We discuss implications of extreme risks for monetary policies in these countries and provide policy suggestions. These risks exist in every monetary economy. On practical grounds, they stem from leptokurtic distribution of financial variables.

Our empirical investigation of the equity market, interest rate and exchange rate risks reaffirms prevalence of significant tail risks in the examined countries, as implied by the leptokurtic data distribution in the conditional volatility series. We find that extreme tail risks associated with interbank rates are more pronounced than those of equity market indexes and exchange rates. Our tests also show that external contagion effects of the 2007-2009 global financial crisis were very strong, triggering excessive volatility in all financial markets of the euro-candidate countries. Evidently, these countries face a continuous challenge of enhancing financial stability and institutional resiliency against global financial contagion.

Monetary policies can help mitigate extreme tail risks in financial markets of the euro-candidates. In order to accomplish this task, monetary policies should aim at preventing anticipated outbreaks of volatility of key financial variables to counteract excessive upswings of credit cycles. Monetary policies following this concept should be reasonably restrictive and aim at preventing an excessive buildup of debt in the economy. However, they should become decisively expansionary at times of financial distress in order to increase the supply of loanable funds and sustain bank lending. Such flexible policy responses are possible when monetary policy conduct departs from rigid instrument rules and resorts to discretionary prevention of financial market distress. Monetary policies aimed at mitigating extreme tail risks ought to be comprehensive and supplemented with appropriate macro- and micro-prudential regulatory responses as they all comprise a financial stability policy framework. Moreover, monetary and regulatory policies ought to be mutually coordinated in order to eliminate asymmetric responses within a cohesive bloc of countries.

In essence, we advocate a new financial stability framework for the euro-candidates, which includes three basic synchronized components: monetary policy, (macro- and micro-) prudential stability policy and international synchronization.

\section{REFERENCES}

Ahrend, R. 2008: Monetary ease - A factor behind financial crisis? Some evidence from OECD countries. Economics E-Journal Discussion paper no. 2008-44. 
Borio, C and Drehmann, M. 2009a: Towards an operational framework for financial stability: 'Fuzzy' measurement and its consequences. Bank for International Settlements Working paper no. 284.

Borio, C and Drehmann, M. 2009b: Assessing the risk of banking crises - Revisited. BIS Quarterly Review March: 29-46.

Borio, C and White, WR. 2003: Whither monetary and financial stability? The implications of evolving policy regimes. In: Monetary Policy and Uncertainty: Adapting to a Changing Economy, Jackson Hole Symposium, Federal Reserve Bank of Kansas City, Kansas City, Missouri, pp. 131-212.

Brunnermeier, M, Crocket, A, Goodhart, C, Persaud, A and Shin, H. 2009: The fundamental principles of financial regulation. Geneva Reports on the World Economy.

Curdia, V and Woodford, M. 2010: Conventional and unconventional monetary policy. Paper to the International Research Forum on Monetary Policy, Federal Reserve Board, Washington, DC, 26 March.

Gabrisch, H. 2009: Finanzielle Instabilität und Krise in den Post-Transformations-Ländern. Wirtschaftspolitische Blätter Jahrg 56(3): 331-347.

Gabrisch, H. 2010: Who owns domestic banks in emerging markets and why does it matter? Paper to the Society for the Studies of Emerging Markets Euroconference, Milas, Turkey, 16-18 July.

Golinelli, R and Rovelli, R. 2005: Monetary policy transmission, interest rate rules and inflation targeting in three transition countries. Journal of Banking and Finance 29(1): 183-202.

Hanousek, J and Kočenda, E. 2011: Foreign news and spillovers in emerging European stock markets. Review of International Economics 19(1): 170-186.

Hanousek, J, Kočenda, E and Kutan, AM. 2009: The reaction of asset prices to macroeconomic announcements in new EU markets: Evidence from intraday data. Journal of Financial Stability 5(2): 199-219.

Hellwig, MF. 2008: Systemic risk in the financial sector: An analysis of the subprime mortgage financial crisis. Max Planck Institute Collective Goods Preprint no. 2008/43.

Jobst, C. 2009: Monetary policy implementation during the crisis of 2007 to 2008. Monetary Policy and the Economy 1: 53-77.

Kindleberger, CP. 1988: The international economic order: Essays on financial crisis and public goods. Harvester Wheatsheaf: Hemel Hemstead.

Kindleberger, CP. 2005: Manias, panics, and crashes. A history of financial crises, 5th Edition (with Aliber, R). John Wiley and Sons: New York.

Kočenda, E, Kutan, AM and Yigit, TM. 2006: Pilgrims to the eurozone: How far, how fast? Economic Systems 30(4): 311-327.

Kočenda, E and Poghosyan, T. 2009: Macroeconomic sources of foreign exchange risk in new EU members. Journal of Banking and Finance 33(11): 2164-2173.

Kočenda, E and Valachy, J. 2006: Exchange rate volatility and regime change: Visegrad comparison. Journal of Comparative Economics 34(4): 727-753.

Minsky, H. 1982a: Can 'it' happen again: Essays on instability and finance. M.E. Sharpe: New York.

Minsky, H. 1982b: The financial-instability hypothesis: Capitalist processes and the behavior of the economy. In: Kindleberger, C and Laffargue, J (eds). Financial Crises: Theory, History, and Policy. Cambridge University Press: New York.

Mishkin, FS. 2009: Is monetary policy effective during financial crises? NBER Working paper no. w14678.

Mizen, P. 2008: The credit crunch of 2007-2008: A discussion of the background, market reactions and policy responses. Federal Reserve Bank of St. Louis Review 90(5): 531-567.

Orlowski, LT. 2005: Monetary convergence of the EU accession countries to the eurozone: A theoretical framework and policy implications. Journal of Banking and Finance 29(1): 203-225.

Orlowski, LT. 2008a: Relative inflation-forecast as monetary policy target for convergence to the euro. Journal of Policy Modeling 30(6): 1061-1081. 
Orlowski, LT. 2008b: Stages of the 2007-2008 global financial crisis: Is there a wandering asset-price bubble? Economics E-Journal Discussion paper no. 2008-43.

Orlowski, LT. 2010a: Monetary policy rules for convergence to the euro. Economic Systems 34(2): $148-159$.

Orlowski, LT. 2010b: Proliferation of tail risks and policy responses in the EU financial markets. European Commission ECFIN European Economy - Economic paper no. 416.

Polito, V and Wickens, MR. 2008: Optimal monetary policy. Using a VAR. CEPR Discussion paper series no. 6957.

Reinhart, CM and Rogoff, KS. 2009: This time is different. Eight centuries of financial folly. Princeton University Press: Princeton and Oxford.

Svensson, LEO. 2003: What is wrong with Taylor rules?: Using judgment in monetary policy through targeting rules. Journal of Economic Literature 41(2): 426-477.

Svensson, LEO. 2010: Inflation targeting after the financial crisis. Speech to the International Conference 'Challenges to Central Banking in the Context of Financial Crisis', Mumbai, India, February 12.

Taylor, JB. 1993: Discretion versus policy rules in practice. Carnegie-Rochester Series on Public Policy 39(1): 195-214.

Taylor, JB. 2009: The financial crisis and policy responses: An empirical analysis of what went wrong. NBER Working paper no. w14631.

White, WR. 2009: Should monetary policy 'lean or clean'? Federal Reserve Bank of Dallas: Globalization and Monetary Policy Institute - Working paper no. 34.

Wolfson, MH. 2002: Minsky's theory of financial crisis in a global context. Journal of Economic Issues 36(2): 393-400. 